\title{
Assessment of knowledge, attitude, and practices towards hydroxy chloroquine pre-exposure prophylaxis for COVID - 19 among health care professionals.
}

Arpita Singh ${ }^{1}$, Hemant Kumar², Preeti Gupta ${ }^{3}$, Ajay Kumar Verma ${ }^{4}$, Atul Jain ${ }^{5}$, Surya Kant ${ }^{6}$, Anuj Kumar Pandey ${ }^{7}$, Shivendra Kumar Singh ${ }^{8}$

${ }^{1}$ Department of Pharmacology, Dr. Ram Manohar Lohia Institute of Medical Sciences, Lucknow, Uttar Pradesh, India; ' ${ }^{2}$ Department of Respiratory Medicine, Dr. Ram Manohar Lohia Institute of Medical Sciences, Lucknow, Uttar Pradesh, India; ${ }^{3}$ Department of Ophthalmology, Hind Institute of Medical Sciences, Sitapur, Uttar Pradesh, India; ${ }^{4}$ Department of Respiratory Medicine, King George's Medical University, Lucknow, Uttar Pradesh, India; ${ }^{5}$ Department of Pharmacology, Dr. Ram Manohar Lohia Institute of Medical Sciences, Lucknow, Uttar Pradesh; ${ }^{6}$ Department of Respiratory Medicine, King George's Medical University, Lucknow, Uttar Pradesh, India, India; ${ }^{7}$ Department of Respiratory Medicine, King George's Medical University, Lucknow, Uttar Pradesh, India; ${ }^{8}$ Department of Community Medicine, King George's Medical University, Lucknow, Uttar Pradesh, India.

\begin{tabular}{|c|c|c|c|c|c|c|c|c|}
\hline Abstract & Introduction & Methodology & Results & Conclusion & References & Citation & \multicolumn{2}{|c|}{ Tables / Figures } \\
\hline \multicolumn{9}{|c|}{ Corresponding Author } \\
\hline \multicolumn{8}{|c|}{$\begin{array}{l}\text { Dr. Ajay Kumar Verma, Additional Professor, Department of Respiratory Medicine, King George's } \\
\text { Medical University, Lucknow, Uttar Pradesh, India } \\
\text { E Mail ID: } \underline{\text { drajay21@gmail.com }}\end{array}$} & 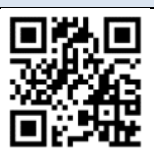 \\
\hline
\end{tabular}

\section{Citation}

Singh A, Kumar H, Gupta P, Verma AK, Jain A, Kant S, Pandey AK, Singh SK. Assessment of knowledge, attitude, and practices towards hydroxychloroquine pre-exposure prophylaxis for COVID - 19 among health care professionals. Indian J Comm Health. 2020;32(4):681-687. https://doi.org/10.47203/IJCH.2020.v32i04.012

Source of Funding: Nil Conflict of Interest: None declared

\section{Article Cycle}

Received: 08/10/2020; Revision: 13/11/2020; Accepted: 27/11/2020; Published: 31/12/2020

This work is licensed under a Creative Commons Attribution 4.0 International License.

\section{Abstract}

Background: There is an urgent need for developing potential drug targets to protect the health care professionals (HCPs) who are at high risk of infection from coronavirus disease-2019 (COVID-19) as they are directly and/ indirectly involved in treatment facility. We aimed to assess knowledge, attitude, and practices towards hydroxychloroquine (HCQ) pre-exposure prophylaxis (PEP) among HCPs directly and/ indirectly involved in COVID19 treatment. Materials and Methods: This cross-sectional study was multi-centric, and data was collected from HCPs (only doctors and nurses) involved directly or indirectly with COVID-19 patient treatment. The study questionnaire consisted of socio-demographic profile; assessment of $\mathrm{HCQ}$ knowledge, attitude, practices, and related adverse drug reactions (ADRs). Results: Of the recruited $374 \mathrm{HCPs}, 302$ fulfilled the study criteria. Mean age of participants was 33.30 \{ \pm standard deviation 7.65 \}. $64.2 \%$ of the participants were male. $16.9 \%$ of the individuals ( $n=51$ ) had co-morbidities. All the HCPs had basic knowledge of COVID-19 and $87.42 \%$ were aware of the role of HCQ as PEP. Further, 269 participants (89.07\%) were aware that HCQ can cause ADRs. 56.6\% participants agreed that HCQ had a protective role against COVID-19 and $54.3 \%$ participants considered that PEP with HCQ had 'more benefit' than risk. 52.32\% ( $n=158)$ HCPs had used HCQ as PEP and $52.53 \%(n=83)$ of these participants had completed the recommended drug course. Twenty participants (12.67\%) had experienced ADR, and 12 had reported it to ADR monitoring centre. Conclusion: Our data shows that HCPs are aware of COVID-19 and HCQ prophylaxis. Approximately $57 \%$ of the participants agreed that HCQ has a protective role against COVID19 and $50 \%$ of the participants had taken HCQ prophylaxis. Only $12.67 \%$ of the participants reported an ADR and in none of them, it was serious enough to discontinue the drug. 


\section{Keywords}

hydroxychloroquine; Pre-exposure Prophylaxis; Health Care Professionals; COVID-19

\section{Introduction}

The burden of coronavirus disease-19 (COVID-19) caused by severe acute respiratory syndromecorona virus-2 (SARS-CoV-2) is continuously increasing across the globe. Approximately $80 \%$ of the COVID-19 patients have mild symptoms that can go unnoticed, but still are able to transmit the disease (1). SARS-CoV-2 secondary infection rates in households ( $15 \%)$, as well as in close contacts $(\sim 10 \%)$ are a major concern (2). In addition to this, $20 \%-43 \%$ infected patients are asymptomatic $(3,4)$. To date, there is no ideal drug nor has been approved for the COVID-19 treatment. Clinical trials of different drugs are underway to check their safety and efficacy towards COVID-19. In this situation, it is essential to start the supportive treatment and repurpose the well-known antiviral drugs and therapy.

Frontline health care professionals (HCPs) e.g. doctors, nurses, pharmacists, and other staff are in direct contact with COVID-19 patients. Due to repeated exposure, the chance of them getting an infection is very high. Health care workers managing COVID-19 patients are getting infected worldwide, with estimates ranging from $4.4 \%-20 \%(5,6,8)$. In this context, chemoprophylaxis could be advantageous to lower the infection rate in HCPs. In pre-exposure prophylaxis (PEP) a drug/therapy is given to prevent the disease. HCQ is a well-known medication used in malaria and chronic inflammatory diseases from many years (9). It is also used as chemoprophylaxis, and anti-rheumatic drug (9). At standard doses, it is safe, and well-tolerated. Recent in-vitro research shows that HCQ can prevent entry of virus as well as its replication, and transmission (10). Additionally, $\mathrm{HCQ}$ increases the $\mathrm{pH}$ of the cellular endosome to prevent virus entry and replication and glycosylation of viral surface receptor angiotensin-converting enzyme-2 (ACE-2). Further, it is also reported that $\mathrm{HCQ}$ is more effective, compared with chloroquine, in suppressing SARS-CoV-2 in-vitro (10). Based on observed concentrations of the drug and in-vitro drug testing, pharmacological models indicates that prophylaxis with $\mathrm{HCQ}$ at permitted doses may prevent SARS-CoV-2 infection(11). Many shreds of evidence have represented the role of $\mathrm{HCQ}$ in the treatment of COVID-19. Adverse effects reported with HCQ include cardiovascular side effects (QT prolongation, arrhythmia, myocardial arrest etc), central nervous system side effects (e.g confusion, convulsions), gastrointestinal side effects (like nausea, vomiting, stomach pain), and retinopathy. Retinopathy is seen with high dose therapy or from long term therapy (9).

The National Task Force (NTF) for COVID-19 constituted by Indian Council of Medical Research (ICMR), New Delhi, India has recommended the use of HCQ prophylaxis for COVID-19 in the following categories- a) asymptomatic healthcare workers involved in containment and treatment zone of COVID-19 as well as other workers working at nonCOVID area of the same hospital, b) asymptomatic frontline workers, such as surveillance workers, and paramilitary/police personnel involved in COVID-19 related activities, c) asymptomatic household contacts of laboratory-confirmed cases(12). The prescribed dose for category-'a' is $400 \mathrm{mg}$ twice for the first day followed by $400 \mathrm{mg}$ once weekly for the next seven weeks after taking food (12). In this study, we have focused on category ' $a$ '. To date, there is very limited data on knowledge, attitude, and practices of HCPs towards PEP with HCQ.

\section{Aims \& Objectives}

1. To assess the knowledge, attitude, and practices of health care professionals towards hydroxychloroquine pre-exposure prophylaxis.

2. To evaluate the adverse drug reactions caused by hydroxychloroquine pre-exposure prophylaxis.

\section{Material \& Methods}

Study design and subjects: It was a multi-centric cross-sectional study. Study protocol was approved from the Institutional Ethics Committee. The schematic representation of work-flow is depicted in [Figure 1]. In the present study, HCPs (doctors and nurses) involved directly or indirectly with COVID-19 patient treatment facilities from tertiary care hospitals were enrolled. As we know that there is very limited data available about the effectiveness of hydroxychloroquine pre-exposure prophylaxis for COVID-19 among HCPs; we aimed to enroll about 300 participants in a duration of one month. To obtain 300 sample size, we had screened 374 HCPs. 
But, 46 participants did not fulfill the eligibility criteria. Hence 328 volunteers filled the predesigned questionnaire. Out of 328 filled questionnaires, 26 were incorrectly and/incompletely filled, so we evaluated data only from 302 HCPs entry.

Enrolled participants were from the age group of 20 to 60 years from both genders. Female participants having a history of amenorrhea or who were pregnant or breastfeeding were excluded from the study. Informed consent was obtained from all the volunteers, those who did not give their consent for participation were also excluded from the study.

Procedure: It was a questionnaire-based study. The study questionnaire consisted of few sociodemographic questions such as age, gender, health profession, co-morbidity, and medication obtained from the health care workers. Further, questions were asked regarding basic knowledge of $\mathrm{HCQ}$, any adverse effect after using it, and its reporting. The questionnaire was developed and validated with the help of experts in the medical field. Data collected was analysed using the SPSS software package (version 5, IBM, Germany). Data is presented as mean \pm standard deviation (SD), median, interquartile range, or number $(n)$ and percentage (\%).

\section{Results}

\section{Demographic profile of HCPs}

Demographic profile was depicted in [Table 1], [Figure-2] [Figure 3]. The mean age of $302 \mathrm{HCPs}$ was 33.30 years $\{ \pm$ standard deviation 7.65 ; median 32 ; interquartile range (IQR) 38-28\}. Number of male ( $n=194,64.24 \%)$ participants was more than females ( $n=108,35.76 \%$ ). Out of 302 HCPs, 193 doctors and 73 nurses were enrolled. $16.89 \%$ participants $(n=51)$ had associated with co-morbidity. Of these 51 participants, 44 had one co-morbidity, 4 had two comorbidities, and 2 had more than two comorbidities. The most common reported comorbidities were hypertension, diabetes, asthma, and hypothyroidism.

\section{Assessment of knowledge}

All the study participants had basic knowledge of COVID-19. When asked about its treatment options, most $(90.4 \%)$ of the participants answered that as of now no treatment is available for COVID-19. $98.68 \%$ of participants had heard about HCQ and $87.42 \%$ had knowledge about its role in pre-exposure prophylaxis in COVID-19. $91.39 \%$ of the HCP responded that HCQ chemoprophylaxis is in the experimental phase. [Table 2]

\section{Assessment of attitude}

$68.54 \%$ of the health care workers agreed that HCQ should be used for pre-exposure prophylaxis of COVID-19 but only $56.95 \%$ of participants thought that HCQ can protect from COVID-19. $81 \%$ HCPs thought that it will lead to a false sense of security, as the drug is in the experimental phase. $54.30 \%$ of participants thought that PEP with HCQ had 'more benefit' (or were in favour of using it) than risk. 269 participants $(89.07 \%)$ were aware that $\mathrm{HCQ}$ can cause adverse drug reactions. [Table 3]

\section{Assessment of practice}

Practice towards HCQ is summarized in [Table 4]. $52.32 \%(n=158)$ health workers had used HCQ towards pre-exposure prophylaxis of COVID-19. Out of these 158, 124 (78.48\%) participants took their doses timely and 83 (52.53\%) participants had completed the drug course. 34 participants had not taken dose timely but completed the drug course. $87 \%(n=138)$ HCPs did not report any ADR after using HCQ. Twenty participants (12.67\%) had experienced ADR while using it. Out of these 20 participants, 14 had reported the ADR to Adverse Monitoring Centre (AMC), or the National Coordination CentrePharmacovigilance Program of India(NCC-PvPI). Rest 6 individuals had not reported it. None of the participants had to stop the PEP HCQ regimen due to ADR. Major ADR reported by participants wereloose motion, palpitation, nausea, and cardiac problems etc. None of the participants reported visual disturbances.

\section{Discussion}

Mean age of the participants in this study was 33.30 years $( \pm 7.65)$ and $64 \%$ of the participants were males. This is similar to the studies done by Pranab Chatterjee et al (13) and Harshith B Kadnur et al (14). In our study, we tried to assess the knowledge, attitude, and practice of HCPs towards HCQ prophylaxis in COVID-19. Our data shows that doctors and nurses have basic knowledge of $\mathrm{HCQ}$ prophylaxis. This was expected as PEP with HCQ is advised by ICMR in India. 57\% HCPs believed that HCQ will protect from COVID-19. $54.30 \%$ of the participants thought that usage of $\mathrm{HCQ}$ as prophylaxis is more beneficial compared to the risk involved with ADRs. In the context of practice, a total of $52.32 \%$ HCPs ( $n=158)$ had used the HCQ as prophylaxis and $52.53 \%(n=83)$ of them had 
completed the drug course recommended by ICMR guidelines. $87.34 \% \mathrm{HCPs}$ who had taken the HCQ did not experience any ADR. However, 20 participants experienced ADR out of which 14 (70\%) had reported it to AMC or NCC under PVPI. This suggests satisfactory reporting of ADR but still underreporting is a big challenge to overcome in PVPI most of the times (15). In the category of ADRs loose motion, indigestion, palpitation, nausea, arrhythmia, skin rashes were major side effects. Several studies have also stated that the use of HCQ is associated with mild ADRs $(13,15-18)$. One of the major concerns raised for use of HCQ as PEP is its safety profile but various studies including ours show that it is safe when used as pre-exposure prophylaxis (16). Also, HCQs have been safely used by rheumatologists even for the long term in patients with chronic autoimmune disease (19). Overall, these results are in support of using HCQ prophylaxis among health care workers to overcome the COVID-19 infection.

\section{Conclusion}

Some evidence to date favours the use of HCQ prophylaxis in COVID-19 patients, while others not. Studies on role of $\mathrm{HCQ}$ prophylaxis in exposed frontline HCPs are satisfactory, although these are few in number. Also, there is dilemma in using $\mathrm{HCQ}$ alone or in combination with azithromycin or others. Our study shows that many HCPs had used HCQ as PEP to prevent COVID-19 and they had experienced only mild ADRs. In conclusion, standard dose of $\mathrm{HCQ}$ may be used to prevent COVID-19 in frontline healthcare professionals especially doctors and nurses during current pandemic. Further research on large scale and clinical trials regarding HCQ prophylaxis is need of hour.

\section{Limitation of the study}

In the frontline healthcare workers doctors, nurses, laboratory members, and other hospital staff are included. However, in this study we have included only doctors and nurses hence result of the study may not be generalized to all HCPs. Hence further studies with comparatively bigger sample size like randomized control trials are needed.

\section{Relevance of the study}

Ideal dose ( $400 \mathrm{mg}$ twice for the first day followed by $400 \mathrm{mg}$ once weekly for the next seven weeks after taking food) of HCQ may be used to prevent COVID19 in frontline healthcare professionals in COVID-19 like pandemic.

\section{Authors Contribution}

AS and AKV designed the study. HK, PG, AKP, SK, AJ, and SKS analyzed the data. All authors wrote and reviewed the manuscript.

\section{Acknowledgement}

We are thankful to all the health care professionals who have participated in the study.

\section{References}

1. Huang $L$, Zhang $X$, Zhang $X$, Wei Z, Zhang L, Xu J, Liang $P, X u Y$, Zhang C, Xu A. Rapid asymptomatic transmission of COVID-19 during the incubation period demonstrating strong infectivity in a cluster of youngsters aged 16-23 years outside Wuhan and characteristics of young patients with COVID-19: A prospective contact-tracing study. J Infect. 2020;80(6):e1-e13. doi: 10.1016/j.jinf.2020.03.006. Epub 2020 Apr 10. PMID: 32283156; PMCID: PMC7194554.[PubMed].

2. Bi Q, Wu Y, Mei S, Ye C, Zou X, Zhang Z, Liu X, Wei L, Truelove SA, Zhang $T$, Gao W, Cheng $C$, Tang $X, W u X$, Wu Y, Sun B, Huang $S$, Sun $Y$, Zhang J, Ma T, Lessler J, Feng T. Epidemiology and transmission of COVID-19 in 391 cases and 1286 of their close contacts in Shenzhen, China: a retrospective cohort study. Lancet Infect Dis. 2020 Aug;20(8):911-919. doi: 10.1016/S14733099(20)30287-5. Epub 2020 Apr 27. Erratum in: Lancet Infect Dis. 2020;20(7):e148. PMID: 32353347; PMCID: PMC7185944.[PubMed].

3. Kim GU, Kim MJ, Ra SH, Lee J, Bae S, Jung J, Kim SH. Clinical characteristics of asymptomatic and symptomatic patients with mild COVID-19. Clin Microbiol Infect. 2020;26(7):948.e1948.e3. doi: 10.1016/j.cmi.2020.04.040. Epub 2020 May 1. PMID: 32360780; PMCID: PMC7252018.[PubMed].

4. Gudbjartsson DF, Helgason A, Jonsson $H$, Magnusson OT, Melsted P, Norddahl GL, Saemundsdottir J, Sigurdsson A, Sulem $P$, Agustsdottir AB, Eiriksdottir B, Fridriksdottir R, Gardarsdottir EE, Georgsson G, Gretarsdottir OS, Gudmundsson KR, Gunnarsdottir TR, Gylfason A, Holm H, Jensson $B O$, Jonasdottir $A$, Jonsson $F$, Josefsdottir $K S$, Kristjansson T, Magnusdottir DN, le Roux L, Sigmundsdottir G, Sveinbjornsson $G$, Sveinsdottir KE, Sveinsdottir $M$, Thorarensen EA, Thorbjornsson B, Löve A, Masson G, Jonsdottir I, Möller AD, Gudnason T, Kristinsson KG, Thorsteinsdottir U, Stefansson K. Spread of SARS-CoV-2 in the Icelandic Population. N Engl J Med. $2020 \quad 11 ; 382(24): 2302-2315 . \quad$ doi: 10.1056/NEJMoa2006100. Epub 2020 Apr 14. PMID: 32289214; PMCID: PMC7175425. [PubMed]

5. Guan WJ, Ni ZY, Hu Y, Liang WH, Ou CQ, He JX, Liu L, Shan H, Lei $\mathrm{CL}$, Hui DSC, Du B, Li LJ, Zeng G, Yuen KY, Chen RC, Tang CL, Wang $T$, Chen PY, Xiang J, Li SY, Wang JL, Liang ZJ, Peng YX, Wei L, Liu Y, Hu YH, Peng P, Wang JM, Liu JY, Chen Z, Li G, Zheng ZJ, Qiu SQ, Luo J, Ye CJ, Zhu SY, Zhong NS; China Medical Treatment Expert Group for Covid-19. Clinical Characteristics of Coronavirus Disease 2019 in China. N Engl J Med. 2020 30;382(18):1708-1720. doi: 10.1056/NEJMoa2002032. Epub 2020 Feb 28. PMID: 32109013; PMCID: PMC7092819.[PubMed].

6. Lancet T. COVID-19: protecting health-care workers. Lancet. 2020;395(10228):922.

7. Remuzzi A, Remuzzi G. COVID-19 and Italy: what next? Lancet. 2020 11;395(10231):1225-1228. doi: 10.1016/S0140- 

6736(20)30627-9. Epub 2020 Mar 13. PMID: 32178769; PMCID: PMC7102589.[PubMed].

8. Keeley AJ, Evans C, Colton H, Ankcorn M, Cope A, State A, Bennett T, Giri P, de Silva TI, Raza M. Roll-out of SARS-CoV-2 testing for healthcare workers at a large NHS Foundation Trust in the United Kingdom, March 2020. Euro Surveill. 2020;25(14):2000433. doi: 10.2807/15607917.ES.2020.25.14.2000433. PMID: 32290904; PMCID: PMC7160437.[PubMed].

9. Ben-Zvi I, Kivity S, Langevitz P, Shoenfeld Y. Hydroxychloroquine: from malaria to autoimmunity. Clin Rev Allergy Immunol. 2012;42(2):145-53. doi: 10.1007/s12016010-8243-x. PMID: 21221847; PMCID: PMC7091063.[PubMed].

10. Yao X, Ye F, Zhang $M$, Cui C, Huang B, Niu P, Liu X, Zhao L, Dong E, Song C, Zhan S, Lu R, Li H, Tan W, Liu D. In Vitro Antiviral Activity and Projection of Optimized Dosing Design of Hydroxychloroquine for the Treatment of Severe Acute Respiratory Syndrome Coronavirus 2 (SARS-CoV-2). Clin Infect Dis. 2020 28;71(15):732-739. doi: 10.1093/cid/ciaa237. PMID: 32150618; PMCID: PMC7108130.[PubMed].

11. Mitjà $\mathrm{O}$, Clotet $\mathrm{B}$. Use of antiviral drugs to reduce COVID-19 transmission. Lancet Glob Health. 2020;8(5):e639-e640. doi: 10.1016/S2214-109X(20)30114-5. Epub 2020 Mar 19. PMID: 32199468; PMCID: PMC7104000.[PubMed].

12. Advisory on the use of Hydroxy-chloroquine as prophylaxis for SARS-CoV-2 infection. Available at: https://www.mohfw.gov.in/pdf/AdvisoryontheuseofHydroxyc hloroquinasprophylaxisforSARSCoV2infection.pdf [Last assessed on 2020 Dec 20]

13. Chatterjee $P$, Anand $T$, Singh KJ, Rasaily R, Singh R, Das $S$, Singh H, Praharajl, Gangakhedkar RR, Bhargava B, Panda S. Healthcare workers \& SARS-CoV-2infection in India: A casecontrol investigation in the time of COVID-19. IndianJ Med Res. 2020;151(5):459-467. doi: 10.4103/ijmr.IJMR_2234_20. PMID:32611916; PMCID: PMC7530442.[PubMed].
14. Kadnur, Harshith B. and Aggarwal, Anivita and Soneja, Manish and Singh, Komal and George, Netto and Nischal, etal. Hydroxychloroquine Pre-Exposure Prophylaxis for COVID-19 Among Healthcare Workers: Initial Experience from India. Available at SSRN: https://ssrn.com/abstract $=3622350$ or http://dx.doi.org/10.2139/ssrn.3622350

15. Jain A, Singh A, Verma AK, Soni M. Assessment of awareness towards pharmacovigilance programme of India and reporting of adverse drug reactions among nurses in a tertiary care hospital. Int J Basic Clin Pharmacol 2018;7:1357-64.

16. Chen J, Liu D, Liu L, Liu P, Xu Q, Xia L, Ling Y, Huang D, Song S, Zhang D, Qian Z, Li T, Shen Y, Lu H. [A pilot study of hydroxychloroquine in treatment of patients with moderate COVID-19]. Zhejiang Da Xue Xue Bao Yi Xue Ban. $2020 \quad 25 ; 49(2): 215-219 . \quad$ Chinese. doi: 10.3785/j.issn.1008-9292.2020.03.03. PMID: 32391667.[PubMed].

17. Bhattacharya R, Chowdhury $S$, Nandi A, Mukherjee $R$, Kulshrestha $M$, Ghosh $R$ et al. Pre-exposure hydroxychloroquine prophylaxis for COVID-19 in healthcare workers: a retrospective cohort. Int J Res Med Sci 2021;9:8996.

18. Nagaraja BS, Ramesh KN, Dhar D, Mondal MS, Dey T, Saha S, Khan MA, Rutul SD, Pratik K, Manjula J, Sangeeth TA, Singh V. HyPE study: hydroxychloroquine prophylaxis-related adverse events' analysis among healthcare workers during COVID-19 pandemic: a rising public health concern. J Public Health (Oxf). 2020 18;42(3):493-503. doi: 10.1093/pubmed/fdaa074. PMID: 32490532; PMCID: PMC7313915.[PubMed].

19. Sun $X, N i Y$, Zhang $M$. Rheumotologitsts' view on the use of hydroxychloroquine to treat COVID-19. Emerg Microbes Infect. 2020;9(1):830-832. doi: 10.1080/22221751.2020.1760145. PMID: 32338155; PMCID: PMC7241459.[PubMed].

\section{Tables}

\section{TABLE 1 DEMOGRAPHIC PROFILE OF STUDIED POPULATION}

\begin{tabular}{|c|c|c|}
\hline S.No. & Characteristics & Subjects ( $n=302)$ \\
\hline 1. & Age (mean $\pm S D$, median, IQR) & $33.30 \pm 7.65,32,38-28$ \\
\hline \multirow[t]{2}{*}{2.} & $\begin{array}{l}\text { Age group (Years) } \\
21-30 \\
31-40 \\
41-50 \\
51-60 \\
61-70\end{array}$ & $\begin{array}{l}120(39.74) \\
142(47.02) \\
32(10.6) \\
5(15.10) \\
3(9.06)\end{array}$ \\
\hline & $\begin{array}{l}\text { Gender (n, \%) } \\
\text { Male } \\
\text { Female }\end{array}$ & $\begin{array}{l}194(64.24) \\
108(35.76)\end{array}$ \\
\hline 4. & $\begin{array}{l}\text { Health profession/occupation (n, \%) } \\
\text { Doctor } \\
\text { Nurse }\end{array}$ & $\begin{array}{l}229(75.83) \\
73(24.17)\end{array}$ \\
\hline 5. & $\begin{array}{l}\text { Co-morbidity (n, \%) } \\
\text { Yes } \\
\text { No } \\
\text { Co-morbidity pattern (n, \%) } \\
\text { One co-morbidity } \\
\text { Two co-morbidity } \\
\text { >2 co-morbidity } \\
\text { Co-morbidity type (n, \%) } \\
\text { Hypertension }\end{array}$ & $\begin{array}{l}51(16.89) \\
251(83.11) \\
44(86.27) \\
5(9.80) \\
2(3.92)\end{array}$ \\
\hline
\end{tabular}




\section{Asthma}

Diabetes mellitus

Hypothyroidism

Arthritis

Ankylosing sponditilitis

Psoriasis

Allergic bronchopulmonary aspergillosis

Potts spine

Osteoporosis

Diabetes, NET

Diabetes, Hypertension

Overweight, Bronchitis

Varicose vein, Diabetes

Diabetes,Asthma,Hypertension

Diabetes, Hypertension,Dyslipidemia,Neuropathy
13(25.5)

10(19.61)

$8(15.67)$

$4(7.84)$

2(3.92)

2(3.92)

2(3.92)

1(1.96)

$1(1.96)$

$1(1.96)$

$1(1.96)$

$1(1.96)$

$1(1.96)$

1(1.96)

$1(1.96)$

TABLE 2 ASSESSMENT OF KNOWLEDGE OF HEALTHCARE PROFESSIONALS TOWARDS COVID-19, AND HYDROXYCHLOROQUINE PROPHYLAXIS.

\begin{tabular}{|l|l|l|l|}
\hline S.No. & Particulars & Yes $(n, \%)$ & No $(n, \%)$ \\
\hline 1 & Do you know about COVID-19? & $302(100)$ & $0(0)$ \\
\hline 2 & Is treatment of COVID-19 available or not available? & $29(9.6)$ & $273(90.4)$ \\
\hline 3 & Have you heard about hydroxychloroquine ? & $298(98.68)$ & $4(1.32)$ \\
\hline 4 & Do you know about its role in pre-exposure prophylaxis for COVID-19? & $264(87.42)$ & $38(12.58)$ \\
\hline 5 & Do you know hydroxychloroquine is in experimental phase? & $276(91.39)$ & $26(8.61)$ \\
\hline
\end{tabular}

TABLE 3 ASSESSMENT OF ATTITUDE TOWARDS HYDROXYCHLOROQUINE PRE-EXPOSURE PROPHYLAXIS AMONG EXPOSED HEALTHGIVING WORKERS FROM COVID-19.

\begin{tabular}{|c|c|c|c|}
\hline S.No. & Particulars & Yes $(n, \%)$ & No $(n, \%)$ \\
\hline 1 & $\begin{array}{l}\text { Do you think that hydroxychloroquine should be used for pre-exposure } \\
\text { prophylaxis of COVID-19? }\end{array}$ & 207(68.54) & $95(31.46)$ \\
\hline 2 & Do you think that it can cause adverse drug reactions? & 269(89.07) & $33(10.93)$ \\
\hline 3 & Do you think it will protect against COVID-19? & $172(56.95)$ & $130(43.05)$ \\
\hline 4 & $\begin{array}{l}\text { Do you think it will lead to false sense of security, as the drug is in the } \\
\text { experimental phase? }\end{array}$ & 245(81.13) & $57(18.87)$ \\
\hline 5 & $\begin{array}{l}\text { What do you think about the benefit: risk ratio of using it? (Yes- More benefit; } \\
\text { No- More risk) }\end{array}$ & $164(54.30)$ & $138(45.7)$ \\
\hline
\end{tabular}

TABLE 4 ASSESSMENT OF PRACTICE OF HYDROXYCHLOROQUINE PRE-EXPOSURE PROPHYLAXIS AND ITS CONSEQUENCES ON DOCTORS AND NURSES.

\begin{tabular}{|c|c|c|c|}
\hline S.No. & Particulars & Yes $(n, \%)$ & No $(n, \%)$ \\
\hline 1 & Have you used hydroxychloroquine as pre-exposure prophylaxis? & $158(52.32)$ & 144(47.68) \\
\hline 2 & If yes, have you taken all the doses in the time? & $124(78.48)$ & $34(21.52)$ \\
\hline 3 & $\begin{array}{l}\text { Have you completed the drug course? } \\
\text { ( } 400 \text { mg BD on first day, followed by } 400 \text { mg once weekly for seven weeks) }\end{array}$ & $83(52.53)$ & 75(47.47) \\
\hline 4 & Have you experienced any adverse drug reactions (ADRs) after using it? & 20(12.67) & $138(87.34)$ \\
\hline 5 & $\begin{array}{l}\text { If yes, what is the ADR you experienced? } \\
\text { Gastric acidity } \\
\text { Allergic reactions } \\
\text { Arrhythmia } \\
\text { Cardiac abnormalities } \\
\text { Indigestion } \\
\text { Diarrhoea } \\
\text { Indigestion, weakness } \\
\text { Itching rashes, nausea }\end{array}$ & $\begin{array}{l}2(10) \\
1(5) \\
1(5) \\
1(5) \\
1(5) \\
1(5) \\
1(5) \\
1(5)\end{array}$ & \\
\hline
\end{tabular}


Skin rashes

Loose motion

Nausea, palpitation

Tinnitus

Palpitation

Palpitation, ECG changes

Palpitation, anxiety

Palpitations, uneasiness

6

Coordination Centre-Pharmacovigilance Programme of India.

\section{Figures}

\section{FIGURE 1 SCHEMATIC REPRESENTATION OF THE WORK-FLOW}

Screening of the health care professionals (HCPs) who were involved in COVID-19 treatment $(n=374)$

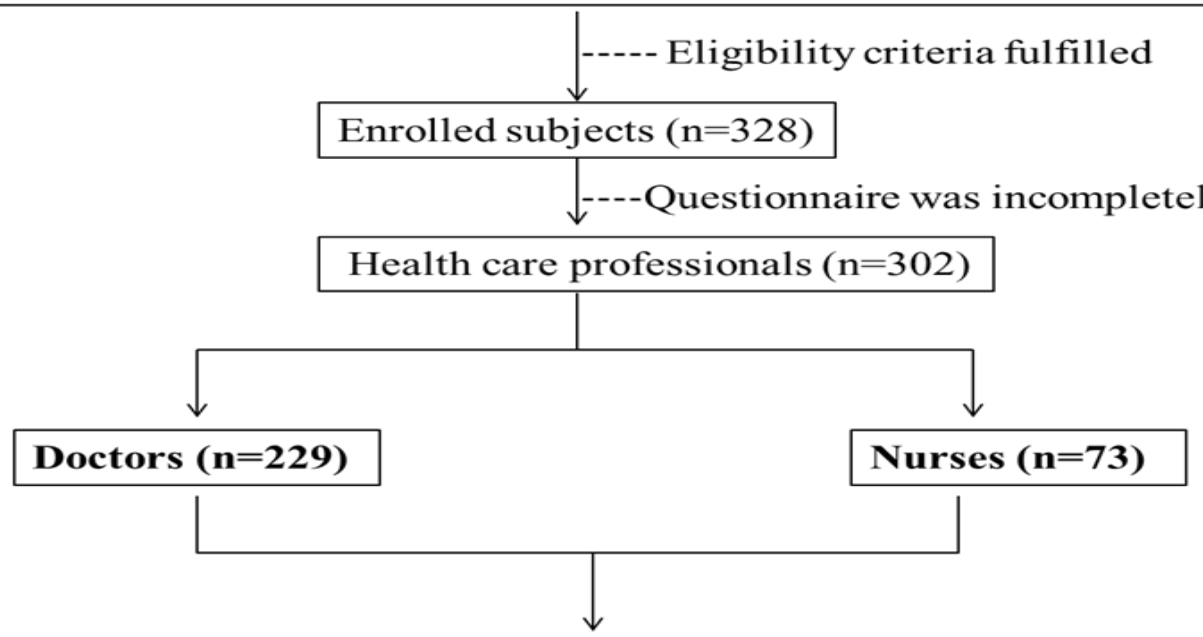

Evaluation of demographic, and clinical profile; knowledge, attitude, and practice towards hydroxychloroquine pre-exposure prophylaxis

\section{FIGURE 2 AGE GROUP OF STUDIED POPULATION}

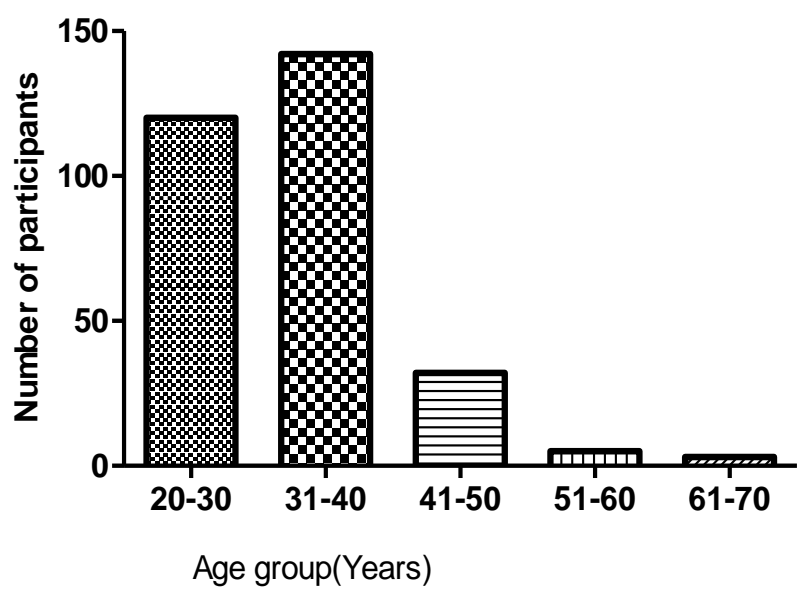

FIGURE 3 ASSOCIATED CO-MORBIDITIES IN THE PARTICIPANTS

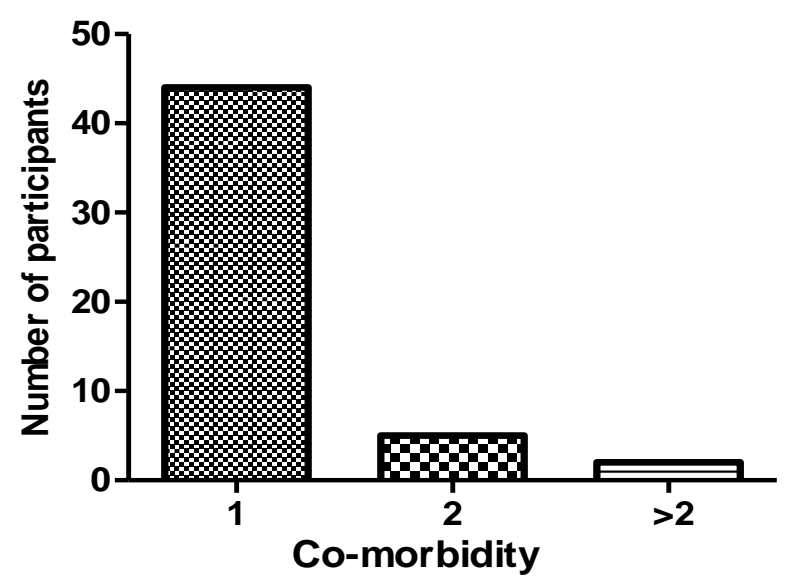

